\title{
Functional proteomics of barley and barley chloroplasts - strategies, methods and perspectives
}

\author{
Jørgen Petersen, Adelina Rogowska-Wrzesinska and Ole N. Jensen*
}

Department of Biochemistry and Molecular Biology, University of Southern Denmark, Odense, Denmark

\section{Edited by:}

Nicolas L. Taylor, The University of

Western Australia, Australia

Reviewed by:

Wolfgang P. Schröder, Umeå

University, Sweden

Clark Nelson, University of Western

Australia, Australia

\section{${ }^{*}$ Correspondence:}

Ole N. Jensen, Department of

Biochemistry and Molecular Biology,

University of Southern Denmark,

Campusvej 55, DK-5230

Odense, Denmark.

e-mail: jenseno@bmb.sdu.dk

Barley (Hordeum vulgare) is an important cereal grain that is used in a range of products for animal and human consumption. Crop yield and seed quality has been optimized during decades by plant breeding programs supported by biotechnology and molecular biology techniques. The recently completed whole-genome sequencing of barley revealed approximately 26,100 open reading frames, which provides a foundation for detailed molecular studies of barley by functional genomics and proteomics approaches. Such studies will provide further insights into the mechanisms of, for example, drought and stress tolerance, micronutrient utilization, and photosynthesis in barley. In the present review we present the current state of proteomics research for investigations of barley chloroplasts, i.e., the organelle that contain the photosynthetic apparatus in the plant. We describe several different proteomics strategies and discuss their applications in characterization of the barley chloroplast as well as future perspectives for functional proteomics in barley research.

\section{Keywords: barley, Hordeum vulgare, proteomics, chloroplast, mass spectrometry, 2D gel electrophoresis}

\section{INTRODUCTION}

Barley (Hordeum vulgare) is one of the earliest domesticated cereals and it is the fourth most important crop world-wide in terms of total dry production, only exceeded by maize, rice, and wheat. Barley is mainly used in the brewing industry and as animal feed, but in certain areas of the world it is an important food source for humans (Schulte et al., 2009). The increasing demand for food due to the growing world population has propelled the implementation of plant breeding programs and biomolecular plant research to improve sustainable crop production. Prioritized areas include research in plant resistance to abiotic stress such as soil salinity, temperature, drought, nutrient uptake (Saeed et al., 2012), and biotic stress caused by other living organisms and pathogens (Dreher and Callis, 2007). Barley is by nature diploid, has a low chromosome number $(2 n=14)$ and a large genome size $(5.1 \mathrm{~Gb})$, is easy to cross-breed and is able to grow under various climatic conditions. These abilities and the fact that barley is an extremely important crop makes it desirable to identify genes responsible for specific beneficial traits in order to improve crop production and sustainability (Saisho and Takeda, 2011). The recently completed whole-genome sequencing of the barley genome (Mayer et al., 2012), gave rise to several interesting observations. A total of 26,159 high confidence genes with gene-family similarity to other plant genomes, and 53,220 genes with lack of homology denoted low confidence genes were identified. By comparison to Arabidopsis thaliana, the barley genome was estimated to encompass 30,400 genes. RNA sequencing data indicated extensive alternative splicing of the coding regions of the high confidence genes (Mayer et al., 2012), this adds to protein diversity and may play a role in protein regulation and gene expression (Syed et al., 2012). These data opens new opportunities for pursuing in-depth studies of barley biology by using genomics, transcriptomics, metabolomics, and proteomics approaches.
The chloroplast is one of the specialized plastids in the plant cell and it conducts important processes such as photosynthesis and biosynthesis of amino acids, starch, and vitamins. The chloroplast contains its own genome, but most of the estimated 2000-3000 chloroplast proteins are encoded by the nuclear genome. Targeting of proteins to the chloroplast often requires $\mathrm{N}$-terminal pre-sequences called chloroplast transit peptides (cTPs), which to some extend can be predicted from the genome by using computational methods such as chloroP, targeP, WoLF PSORT, iPSORT, predotar, or Protein Prowler (Emanuelsson et al., 1999; Bannai et al., 2002; Small et al., 2004; Boden and Hawkins, 2005; Horton et al., 2007).

Functional proteomics is a rapidly evolving scientific discipline that is driven by advancements in a series of bioanalytical and computational technologies to enable increasingly detailed studies of complex protein mixtures derived from cells, tissues, and organisms (Aebersold and Mann, 2003; Cravatt et al., 2007; Bensimon et al., 2012). The main methods used in proteomics are: (1) protein and peptide separation techniques; (2) mass spectrometry; (3) biological sequence databases and computational query tools (summarized in Boxes $\mathbf{1}$ and 2).

Proteomics technologies are now extensively used in plant biology, particularly in studies of the model plants and the most important food crops (Jorrin et al., 2007). Proteomics, i.e., the systematic study and characterization of proteins in a cell type, tissue, or a whole organism, encompasses the mapping of protein composition and abundance, protein interactions and protein localization, as well as dynamic events in protein regulatory networks, including signaling mechanisms, metabolism, and transcription (de Hoog and Mann, 2004). A majority of such studies in plants were carried out in A. thaliana and rice where completely sequenced genomes are available (Kaul et al., 2000; Goff et al., 2002). Proteome analysis of plant organelles, including 


\section{BOX 1 | Mass spectrometry.}

Mass spectrometry enables unambiguous identification of proteins by accurate mass measurements of gas-phase protein and peptide ions and peptide fragment ions. Mass spectrometers using matrix-assisted laser desorption ionization (MALDI) are preferred for simple peptide mixtures derived by in-gel digestion of proteins obtained from 2D gel spots (Gevaert and

Vandekerckhove, 2000). Electrospray ionization (ESI) mass spectrometers are frequently interfaced directly to nanoliter-flow HPLC systems, thereby providing separation, mass determination, and amino acid sequencing in one analytical setup (LC-MS/MS) (Aebersold and Mann, 2003). Besides being able to identify thousands of proteins in one single LC-MS/MS analysis, modern proteomics workflows also provides rather accurate protein quantification and capability to identify PTMs (Larsen et al., 2006; van Bentem etal., 2006; Ytterberg and Jensen, 2010; Mithoe and Menke, 2011). These features make MALDI and ESI mass spectrometry indispensable in proteomics research for the characterization and quantification of complex protein mixtures.

chloroplasts, have been reported (Kleffmann et al., 2004). For example, proteomics strategies were used to elucidate the influence of various biotic and abiotic stresses on chloroplasts proteins.

The recently completed sequencing of the barley genome now provides a foundation for more detailed functional proteomics studies of barley biology. We therefore foresee an increased effort in barley proteomics using state-of-the-art mass spectrometry based strategies for qualitative and quantitative characterization of barley proteins, organelles and regulatory networks. Proteomics will likely play a major role in further improvements of barley cultivars, e.g., by identifying the underlying mechanisms of biotic and abiotic stress. In the following sections we provide an overview of proteomics strategies and techniques and the current state of barley chloroplast proteomics.

\section{GENERAL CONSIDERATIONS AND PROTEOMICS STRATEGIES}

Several factors affect the outcome of a proteomics experiment, and need to be included in the experimental planning phase, like for example proteome complexity and protein concentration (summarized in Box 3). This section covers two classical proteomics strategies and highlights things to consider before starting a chloroplast-targeted proteomics experiment.

Purification: The first step toward success in organelle or sub proteomic experiment is the quality and purity of the sample. Contaminating proteins or unwanted cellular debris can obscure the results with respect to assignment of organelle specific proteins and their quantification (Agrawal et al., 2011). Highly purified chloroplasts or mitochondria can be obtained using a Percoll gradient centrifugation step (Neuburger et al., 1982; Aronsson and Jarvis, 2002; van Wijk, 2004; Millar et al., 2005). Endomembrane organelles such as Golgi apparatus, endoplasmic reticulum, vacuoles, and vesicles are more difficult to purify without cross-contamination from other organelles. Gentle rupture of the intact chloroplasts enables further purification of four subcompartments (1) the inner and outer envelope membranes, (2) the stroma, (3) the thylakoid membrane, (4) the thylakoid lumen (Kieselbach et al., 1998, 2000; Peltier et al., 2000, 2006; Schubert

\section{BOX 2 | Quantitative proteomics.}

2D gel electrophoresis is the preferred method for comparative quantitative proteomics in studies of organisms for which only incomplete gene annotation is available, e.g., for carrots and cabbage (Nawrocki et al., 2011). The advantage of using 2D gel electrophoresis is the one spot - one protein premise that makes it relative easy to make sequence homology searches, de-novo sequencing of fragmented peptides or protein isoform characterization (Jacob and Turck, 2008; Moller et al., 2011b). Mass spectrometry driven quantitative proteomics methods can be categorized into "label-free" approaches based on peptide intensity or peptide counting and "stable isotope labeling" methods where proteins and/or peptides are metabolically or chemically encoded by heavy stable isotopes of, e.g., carbon, nitrogen, and oxygen (13-C, 15-N, 18-O; Ong and Mann, 2005; Thelen and Peck, 2007; Bantscheff et al., 2012). Commonly used metabolic labeling methods in plant proteomics include stable isotope labeling by 15-N (Nelson et al., 2007; Bindschedler etal., 2008; Gouw et al., 2008) and by amino acids in cell culture [stable isotope labeling by amino acids in cell culture (SILAC); Ong et al., 2002], although the latter is not easily implemented in plants due to their amino acid metabolism (Gruhler et al., 2005). Chemical methods for stable isotope labeling are generically applicable in plant proteomics and include iTRAQ (Ross et al., 2004; Wiese et al., 2007) and isotope-coded protein labeling (ICPL; Schmidt et al., 2005). Examples include phosphoproteomics (Jones et al., 2006; Melo-Braga et al., 2012), global protein regulation in response to stress (Neilson etal., 2011; Abdalla and Rafudeen, 2012) or as a consequence of genotypic differences (Chen etal., 2009; Ng et al., 2012).

The advantage of label-free approaches is that they are rather straightforward to implement, however, their robustness and accuracy relies on multiple replicate runs and comparative data analysis is often rather complex. Nevertheless, recent improvements in software and statistics for label-free proteomics make this a very attractive approach. The main advantages of stable isotope labeling techniques are their accuracy of quantification and the ability to perform multiplex experiments. iTRAQ allows up to eight-plex analysis in one LC-MS/MS experiment (Bantscheff et al., 2007; Pottiez et al., 2012).

et al., 2002; Ferro et al., 2003). The above mentioned extractions method were used for diverse plant species, and it is important to have in mind that protocols developed for a specific plant species, not necessarily works for other species. Typically intact chloroplasts are obtained using Percoll gradient centrifugation. This is by far the best way to obtain pure chloroplasts, but the yield is rather low. Less pure chloroplast can be obtained in high yields using low speed centrifugation. It is possible to obtain thylakoid, stroma, and envelope fractions using a sucrose gradient of osmotic shocked intact chloroplasts. Soluble luminal thylakoid proteins can be isolated from the thylakoid preparation using yeda press rupture of the membranes (Hall et al., 2011).

How much material is needed? It is possible to make quantitative proteomics experiments with less than $20 \mu \mathrm{g}$ of extracted protein. The number of identified proteins from such an experiment depends not only on the complexity and dynamics of the proteome but also the in-house instrumentation (Eriksson and Fenyo, 2010). In sub proteomic work the amount of starting material might exceed several grams to extract a few micro grams of 


\section{BOX 3 | Proteome complexity and protein concentrations.}

Due to the high complexity and wide concentration range of proteins within proteomes, large scale proteome analysis is often executed at the sub-proteome level (James, 1997; Kuntz and Rolland, 2012) where specific cellular or tissue fractions are isolated and analyzed. For example, enrichment strategies can be used to isolate sub-proteome consisting of, e.g., kinases, or proteins containing specific modifications (e.g., phosphorylation or glycosylation), body or tissue fluids (e.g., sap) or organelles such as cell nuclei, mitochondria, Golgi apparatus, or chloroplasts. The need for fractionation into sub-proteomes becomes obvious when considering that the potential number of different proteins from a single genome coding for 20,000-30,000 genes, might be as high as $200,000-2$ million when considering genomic recombination, splice variants, differential initiation/termination of transcripts and protein processing and covalent modifications (Ayoubi and Van De Ven, 1996; Lander et al., 2001). In addition, the concentration ranges of proteins in eukaryotic cells typically span five-six orders of magnitude and in some sub-proteomes as high as 10 orders of magnitude. In some plants it has been estimated that RuBisCO makes up $40 \%$ of the total protein content, making the stroma in the chloroplast a very challenging protein matrix to analyze (Patterson and Aebersold, 2003; Bindschedler and Cramer, 2011). By reducing protein complexity by sub-proteome fractionation it is possible to identify low abundant proteins in the proteome of an organism.

a desired proteome. As an example, from $100 \mathrm{~g}$ of soil grown $A$. thaliana plants it is possible to extract approximately $1000 \mathrm{mg}$ leaf protein, $100 \mathrm{mg}$ thylakoid proteins, and only $0.4 \mathrm{mg}$ envelope membrane protein (Froehlich et al., 2003).

What buffers should I use? There is no universal buffer composition to be used in proteomics experiments. Depending on the targeted tissue or sub-cellular compartment different protein extraction and sample preparation buffers are used (Fido et al., 2004; Mano et al., 2008). However, there are few universal rules that should be taken into consideration. Always add protease inhibitors, but be aware of the lifetime of the inhibitors, it might be short under certain conditions, or use strong denaturing buffers [e.g., $8 \mathrm{M}$ urea or sodium dodecyl sulfate (SDS)] to inactivate potential proteolytic activity of enzymes present in the sample. Use metal chelating agents, e.g., ethylenediaminetetraacetic acid (EDTA) to trap free metal ions from the sample to prevent unwanted spontaneous protein oxidation - this is particularly important when working with organelles such as chloroplasts and mitochondria. Most buffers used in biological experiments contains components which are not compatible with liquid chromatography-mass spectrometry (LC-MS) but if the proteins are separated by polyacrylamide gel electrophoresis (PAGE) all buffers are allowed, due to the excellent washing ability of gel plugs. For non-gel based strategies some compounds such as detergents (SDS, Triton X-100, etc.) or ampholytes compromise nanoliter-flow LC or mass spectrometry and they need to be avoided or removed prior to analysis (Xiao et al., 2004; Yeung and Stanley, 2010).

Can high abundant proteins be removed? In photosynthetic tissue the predominant protein is the carbon fixation protein ribulose-1,5-bisphosphate carboxylase/oxygenase (Rubisco). In some cases more than $50 \%$ of the total leaf protein content consist of Rubisco (Metodiev and Demirevskakepova, 1992). Such highly abundant protein will hamper both gel and non-gel based proteome analysis because this highly abundant protein will obscure other proteins and suppress their detection. In gel based studies it will dominate the gel pattern eclipsing low abundant proteins with similar physico-chemical properties. In non-gel based peptides generated from this abundant protein will saturate high performance liquid chromatography (HPLC) columns and suppress the signal from lower abundant proteins. This problem can be partially solved by removing the highly abundant protein by fractionation, antibody based spin columns, or using the relative newly developed ProteoMiner beads (Boschetti and Righetti, 2008; Frohlich et al., 2012). Removal of highly abundant proteins can also result in removal of the associated low abundant proteins (Cellar et al., 2008; Krishnan and Natarajan, 2009). Another way to reduce the complexity and the dynamics of protein sample is to perform organelle or sub-organelle fractionation. Isolation of mitochondria or a thylakoid preparation from chloroplast will exclude the majority of Rubisco protein from the analysis.

How to proceed after proteome extraction? Proteins, both for gel and non-gel based strategies (see below) need to be digested into peptides prior to mass spectrometry analysis. The aim is to generate ionizable peptides in the mass range 700-2500 Da, which is the optimal range for most biological mass spectrometers. Disulfide bridges (Cys-Cys) in proteins are typical reduced and alkylated using dithiothreitol (DTT) and iodacetamide (IAA) prior to digestion. Denaturation of the proteins improves digestion efficiency, thus contributing to the overall protein identification rate. Proteins separated by SDS-PAGE are inherently denatured and are typically cut out of the gel, reduced, $S$-alkylated and digested by trypsin. This is a well-established "in-gel digestion" technique routinely used by most proteomics laboratories (Shevchenko et al., 1996, 2006). In solution based digestion is a more delicate procedure. Keeping the proteins in solution, denatured and available for trypsin digestion can be facilitated by buffers containing the commercially available surfactant RapiGest, urea buffers or detergents such as sodium deoxycholate (SDC) that, in contrast to SDS can relatively easy be removed from the sample prior to the mass spectrometry analysis (Speers and Wu, 2007; Norrgran et al., 2009; Lin et al., 2012). In-solution digestion protocols where the digestion is performed within a spin filter device has become popular and is highly recommended for the digestion of protein amounts exceeding $100 \mu \mathrm{g}$. The filter enables washing of the sample and retention of large unwanted structures on the filter (Manza et al., 2005; Wisniewski et al., 2009).

How do I evaluate the quality of the experiment? Proteomics experiments often aim to detect differential regulated proteins between groups. This can be accomplished using a statistical test based on hypotheses about characteristics of both the biological samples that represent the population, and the variability of the technical measurements (Podwojski et al., 2012).

If possible, evaluate the protein extract by electrophoresis; this gives an overall picture of the extract. Non-gel based approaches can benefit using an internal spike-in protein standard. The protein standard is digested together with the extract, and by comparing sequence coverage and peptide intensities of the spiked-in 
standard among samples, the digest efficiency can be evaluated. This can be archived using selected reaction monitoring (SRM) or other label-free quantification methods. Absolute quantification can be archived using spiked-in peptides that act as internal standards (Gerber et al., 2003; Silva et al., 2006).

\section{PROTEOMICS STRATEGIES}

The choice of proteomic strategy depends on several factors such as the overall aim of the proteomics experiment, protein sample complexity and protein amount, number of samples to analyze, mass spectrometry instrument considerations, sequence database availability and whether protein quantification is necessary (Figure 1).

$2 \mathrm{D}$ gel electrophoresis is a separation technique that is based on isoelectric focusing of the proteins followed by separation of the proteins according to their molecular mass. It has been used in proteomics for more than 30 years. Although a number of its limitations have been recognized (reviewed in Issaq and Veenstra, 2008; Chevalier, 2010) it is an effective strategy for the separation and quantitation of intact protein mixtures, including protein isoforms and modified proteins. A variation of the classical denaturing $2 \mathrm{D}$ PAGE is blue native $(\mathrm{BN})$ 2D PAGE (Reisinger and Eichacker, 2007). This technique has been used in several membrane proteins studies (Krause, 2006), and is also one of the preferred ways for characterization of protein complexes. Protein separated by electrophoresis are visualized by staining, isotope or fluorescent labeling (Patton, 2002). Often only the differential regulated proteins are selected for spot picking, protein digestion, and protein identification (Berth et al., 2007). The advantage using the 2D gel strategy is the one spot - one protein premise, which allows for relatively easy de novo annotation of peptide fragment spectra and homolog search.

The combination of SDS-PAGE and LC-MS is very efficient for proteome profiling. The combination is often called GeLCMS/MS, and is excellent for proteome profiling due to the unbiased solubilization of all protein groups including membrane proteins. For quantitative measurements it can be used with metabolically incorporated stable isotopes, isobaric tags for relative and absolute quantitation (iTRAQ) and semi quantitative approaches such as spectral counting (Sachon et al., 2006; Wienkoop et al., 2006).

Recently, 2D LC-MS/MS strategies have become more widespread and robust. The orthogonality between the two LC separation dimensions is often obtained by using strong cation exchange chromatography (SCX) in the first dimension and reverse phase (RP) chromatography in the second dimension, separating the peptides according to charge and then according to hydrophobicity (Washburn et al., 2001). Other types of resin, e.g., hydrophilic interaction liquid chromatography (HILIC) and size-exclusion chromatography (SEC) have also been used in proteomic studies (Gilar et al., 2005a). More recently, RP-RP HPLC systems using high $\mathrm{pH}$ and low $\mathrm{pH}$ mobile phases in the first and second separation dimensions, respectively, have proved to be excellent and robust for proteomics work (Gilar et al., 2005b). This set up can be fully automated and is suitable for proteomics work where several biological replicates are needed. It can be combined with both label based and label-free quantification methods. It is also possible to achieve absolute quantification of the identified
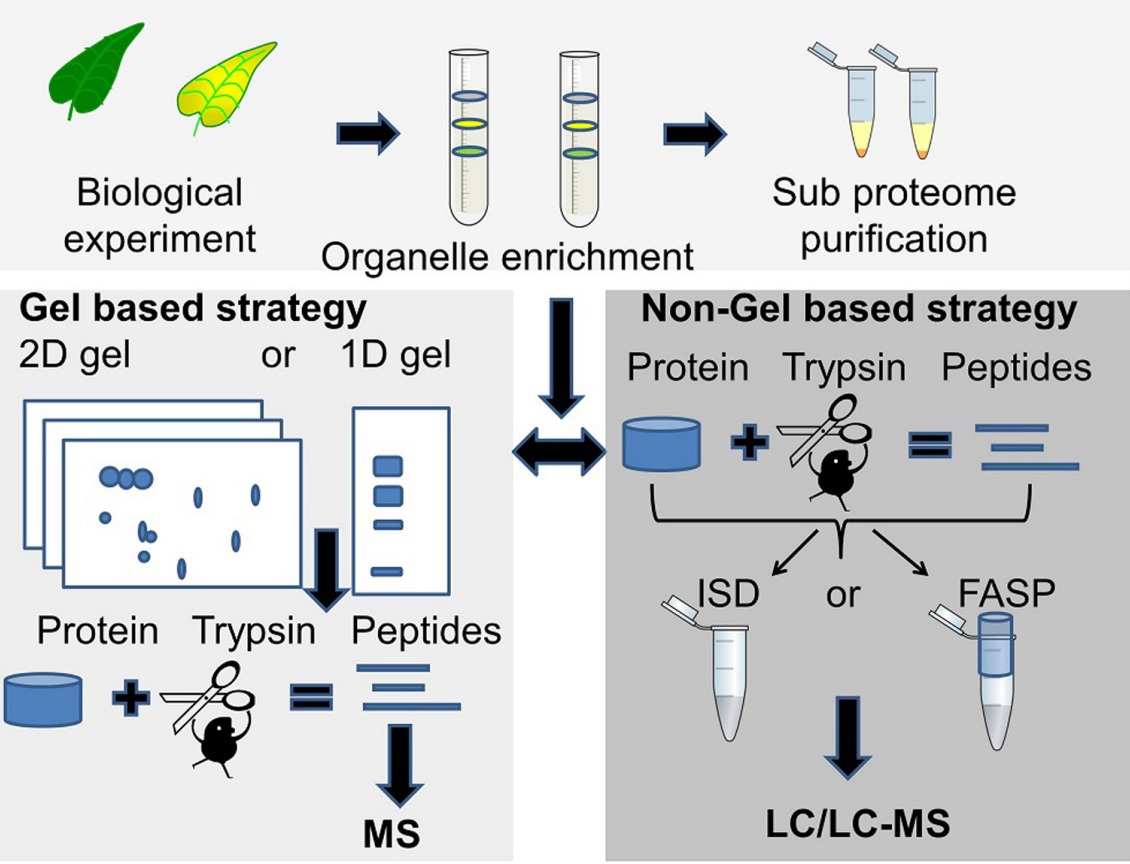

FIGURE 1 | Two commonly used proteomics strategies. The gel based strategy (lower left panel), where protein bands or spots are cut out of the gel followed by trypsin digestion and MS analysis of peptides, and the MS based strategy (lower right panel) where the unseparated or partially fractionated protein sample is "in-solution digested" (ISD) with trypsin or digested in a spin filter [filter-aided sample preparation (FASP)] followed by LC/LC-MS/MS for peptide separation and sequencing. 
proteins by spiking in known amounts of digested protein standards (Silva et al., 2006). Separation using only one dimension is also possible, but for complex samples or samples with high dynamic range, the number of protein identifications will be limited due to lower peak capacity compared to 2D LC strategies where two orthogonally retention mechanisms are used.

Mass spectrometry data contains peptide information at the MS and at the MS/MS level. For protein identification the MS and MS/MS data can be searched using commercial or publicly available search engines such as Sequest, Mascot, OMSSA, or X!tandem (Cottrell, 2011). Software designed for handling large proteomics datasets integrates multiple features such as identification, quantification, visualization, statistics, and reporting. These include packages such as Phenyx, Trans-Proteomic Pipeline (TPP) MaxQuant, and Peaks (Lemeer et al., 2012).

\section{CURRENT STATUS OF BARLEY PROTEOMICS}

The areas where barley proteomics has been used can be divided into (a) industry driven biotechnology, including seed germination and maturation, beer proteomes, and malting proteomes and (b) biology driven proteomics covering plant adaptation to abiotic stress and organelle function including the chloroplast that is the focus of this review.

Biotechnology driven proteomics: Understanding the mechanisms involved in seed germination and maturation processes are important aspects in the malting industry where, e.g., enzyme amount such as amylase in different cultivars influences the conversion of starch into fermentable sugars. The work with proteome analysis of different barley seed cultivars and proteomes from different developmental stages of germinating barley started in year 2002 (Finnie et al., 2002; Ostergaard et al., 2002). 2D gels were used as a protein profiling tool. The proteins were extracted using a low salt buffer, favoring the extraction of water soluble seed proteins such as amylases and chitinases, and minimized extraction of high abundant storage proteins such as hordeins that otherwise would dominate the protein profile in the $2 \mathrm{D}$ gel. The TrEMBL database at that time only contained 546 barley protein sequences, so therefore most of the protein identifications were based on cross-species protein annotation using other cereals, such as rice, maize, and wheat. The strength of 2D gel electrophoresis was also pointed out in these studies, since the same protein was identified in multiple protein spots, maybe as a consequence of post-translational modifications (PTM) or multiple alleles with almost identical protein sequences.

Hynek et al. (2009) reported the enrichment of hydrophobic membrane proteins from the barley plasma membrane fraction, which may play a key role in the germination process, by using two-phase partitioning and RP chromatography. The enrichment of the membrane fraction was validated using western blotting against $\mathrm{H}^{+}$-ATPase, a protein located in the membrane. Sixtyone barley proteins were identified after SDS-PAGE by using electrospray tandem mass spectrometry (ESI-MS/MS).

Protein profiles of different beers are diverse due to differences in the barley cultivar, the malting process and the brewing yeast. 2D gel maps of different beer proteomes representing different cultivars and malting types have been created. The maps can be used as quality control step in the brewing industry and as a tool to detect and identify beer type specific proteins or protein isoforms that might represent taste, flavor, or texture. In the long term this will potentially enable manipulation of, e.g., flavor proteins (Fasoli et al., 2010; Iimure et al., 2010). The industrial induced protein modification called Maillard reactions has also been monitored and characterized and is important for color, taste, and flavor and include thermal stability of proteins and the non-enzymatic glycation of proteins (Perrocheau et al., 2005; Okada et al., 2008; Petry-Podgorska et al., 2010)

Biology driven proteomics: 2D gel electrophoresis was the preferred method to study the proteome of barley plants exposed to salinity stress and adaptation (Fatehi et al., 2012). Barley plants, a tolerant and a salt-sensitive genotype, were exposed to 0 (control) or $300 \mathrm{mM} \mathrm{NaCl}$. More than 500 reproducible protein spots were detected of which 44 appeared to be regulated. The regulated proteins were involved in several biological processes such as reactive oxygen species scavenging, signal transduction, and protein processing. The advantage of this $2 \mathrm{D}$ gel strategy for studying a non-sequenced organism was pointed out - only the regulated proteins needed to be analyzed and identified by mass spectrometry. A similar procedure was used in a nitrogen use efficiency study of barley, where proteomes from barley shoots and roots were analyzed using $2 \mathrm{D}$ gels. Comparative proteome analysis of plants grown with a nitrogen source and plants grown under nitrogen deficiency revealed 67 and 49 differentially regulated protein spots in roots and shoots, respectively (Moller et al., 2011a). Proteins associated with drought have also been analyzed using $2 \mathrm{D}$ gel proteomics (Wendelboe-Nelson and Morris, 2012). In a comparative study of barley, extracted leave and root proteomes from boron tolerant and boron intolerant barley plants were studied using an iTRAQ based method and peptide fractionation by $2 \mathrm{D}$ LC prior to mass spectrometry analysis. A total of 138 proteins were identified from leaf tissue and 341 were identified from root tissues. Only 11 out of 1038 peptides from the root tissue were regulated in the boron tolerant barley plant. Interestingly seven of these peptides identified three proteins involved in iron deficiency response (Patterson et al., 2007).

Protein modifications such as acetylation, glycosylation, and phosphorylation are important regulators of a wide range of biological processes in plants (Ytterberg and Jensen, 2010). In barley only a handful of proteomics studies deal with protein modifications. These include protein characterization in seeds during maturation using 2D gels (Finnie etal., 2006; Laugesen et al., 2007), where spot "trains" of the same proteins appeared during maturation as a consequence of small amino acids sequence differences, processing and differences in the degree of protein glycosylation. Phosphoprotein studies in tonoplasts revealed a total of 65 phosphopeptides, and provide a first view into the regulation of several metabolic pathways in tonoplast (Endler et al., 2009). Phosphoproteomics in plants were recently reviewed (KlineJonakin et al., 2011).

\section{THE BARLEY CHLOROPLAST PROTEOME}

Only a few studies concerning the barley chloroplast proteome have been published, and a comprehensive list of barley chloroplast proteins is yet to be reported. In contrast, global proteomics in Arabidopsis has been a reality for more than 20 years due to 
the complete sequencing of the A. thaliana genome at the beginning of this millennium. (Kaul et al., 2000; Wortman et al., 2003). Chloroplast proteome work in barley, wheat, and A. thaliana will be discussed below. Figure 2 compares the number of proteins identified in the chloroplast sub-compartments from these three species.

The envelope membrane: The envelope membrane of the chloroplast is the site of several important functions such as biosynthesis of glycerolipids, fatty acid export, metabolite transport, and protein import. In A. thaliana, Ferro et al. (2010) reported 644 proteins to be associated with the membrane envelope using both in-gel and in-solution digestion of proteins. Earlier studies of the envelope membrane using both geLC-MS/MS and 2D LC-MS/MS produced fewer identifications (Ferro et al., 2003; Froehlich et al., 2003).

The thylakoid membrane: The thylakoid membrane contains the photosynthetic machinery, but also proteins involved in regulation and maintenance of this machinery. In thylakoid preparations from $A$. thaliana the number of identified proteins sums up to 242 using geLC-MS/MS and LC-MS/MS and 154 proteins using 2D gels (Friso et al., 2004; Peltier et al., 2004). A total of 198 thylakoid luminal proteins have been identified combing data from several studies (Peltier et al., 2002; Giacomelli etal., 2006). Some of these are believed to be up to 10,000-fold less abundant than photosynthetic proteins, and can only be identified by sub-proteome isolation. Other studies on luminal proteins report less proteins (Schubert et al., 2002), which might reflect differences in purification and proteomics strategies.

The thylakoid membrane of barley was investigated by the use of BN 2D PAGE, with the aim to compare the photosynthetic machinery of barley with that of other higher plants (Ciambella et al., 2005). The number of barley thylakoid proteins identified was 45, of these 17 proteins from photosystem II (PSII), 16 from PSI, 7 proteins from cytochrome B6, and 5 from the
ATP synthase. The same number of barley thylakoid proteins was reached in another study (Granvogl et al., 2006). One recent study from 2011 (Ploscher et al., 2011) compares protein complexes from etioplast and chloroplast. This is at the moment the most comprehensive chloroplast proteome study in barley. Etioplasts develop in the absence of light but can mature into chloroplasts by illumination. By using 2D BN/SDS-PAGE to separate the protein membrane complexes from etioplast and chloroplast, they found eight etioplast/chloroplast shared protein complexes, among those with high number of subunit representation were the ATPase, cytochrome b6, and the NAD $(\mathrm{P}) \mathrm{H}$ dehydrogenase complex, whereas the PSI and PSII complexes were only present in the chloroplast. The use of $\mathrm{BN}$ gels made it possible to quantify and distinguish between monomeric, dimeric, and multimeric forms of the photosynthetic protein machinery, and to distinguish between the different subunits present in the protein complexes, making assumptions of assembly and maturation of protein complexes possible. Both automated and manually inspected fragment spectra were generated from the mass spectrometry based analysis where both online protein identification of tryptic digested proteins and off-line identification of intact small proteins extraction from gel were identified. In an earlier study by the same group (Ploscher et al., 2009), intact low molecular weight proteins from PSII were identified using off-line ESI MS.

The stroma: The stroma contains the genetic material and important metabolic enzymes including those involved in the Calvin cycle. Using the geLC-MS/MS approach a total of 590 A. thaliana proteins were identified (Zybailov et al., 2008). Less protein identifications were obtained in an attempt to identify paralogs using 2D native gels (Peltier et al., 2006). For barley no stromal proteome studies have appeared to date, but four proteins from the above mentioned preparations (Ciambella et al., 2005; Ploscher et al., 2011) are supposedly targeted to the stroma.

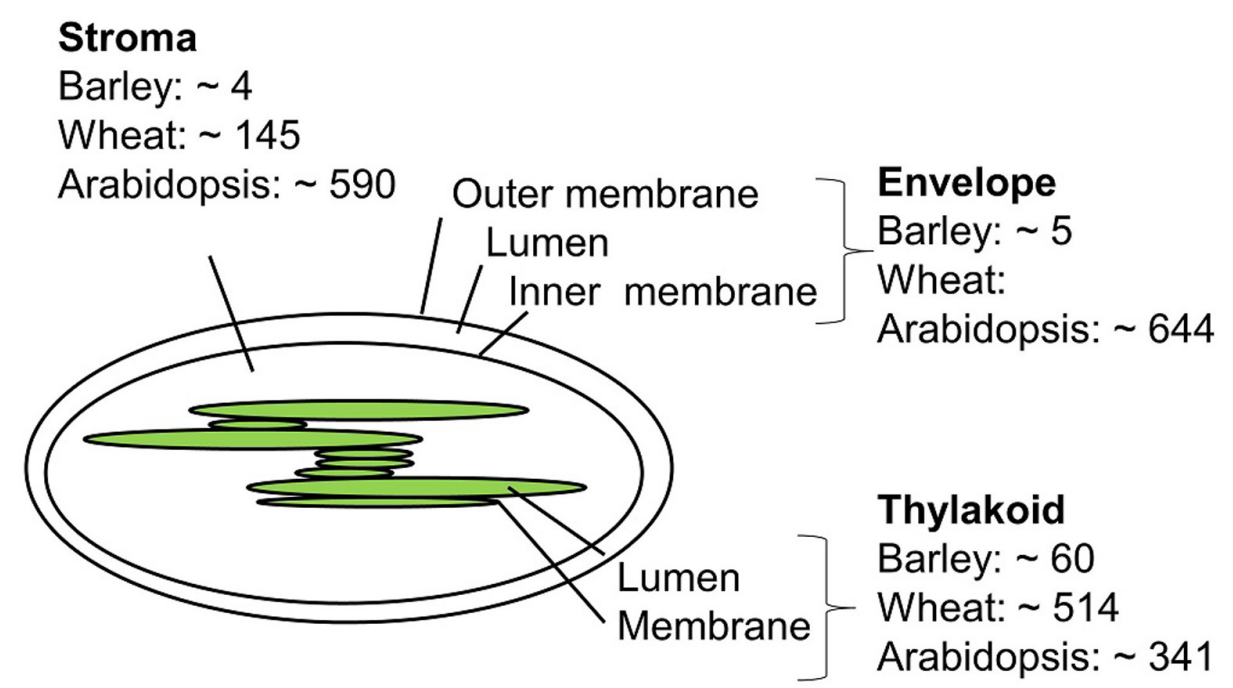

FIGURE 2 | Approximate number of chloroplast proteins identified in barley (Ciambella et al., 2005; Bartsch et al., 2008; Ploscher et al., 2011), wheat (Kamal et al., 2012), and Arabidopsis (Peltier et al., 2004; Giacomelli et al., 2006; Zybailov et al., 2008; Ferro et al., 2010). 
In a recent chloroplast proteomic study in wheat, which shares sequence similarity with barley, the geLC-MS/MS strategy was used, and a total of 607 chloroplast proteins were identified. Of these, 145 were from stroma, 342 were from the thylakoid membrane, 163 from the lumen, and 166 proteins were integral membrane proteins (Kamal et al., 2012).

Armbruster et al. (2011) summarizes all proteomics work on chloroplast and comes up with a total number of nucleus encoded proteins to be $1741,63 \%$ with predicted cTP.

\section{THE FUTURE FOR PROTEOMICS OF BARLEY AND BARLEY CHLOROPLASTS}

Proteomics work in barley has to date been hampered by the lack of complete genomic sequence. But by the complete sequencing of the barley genome the goal to identify all of the predicted 2000-3000 chloroplast protein is within reach. The shift in analytical methods in proteomics from 2D gels toward 2D LC-MS/MS based strategies, due to completely sequenced genomes, improved nano-LC systems and faster and more sensitive tandem mass

\section{REFERENCES}

Abdalla, K. O., and Rafudeen, M. S. (2012). Analysis of the nuclear proteome of the resurrection plant Xerophyta viscosa in response to dehydration stress using iTRAQ with 2DLC and tandem mass spectrometry. J. Proteomics 75, 23612374 .

Aebersold, R., and Mann, M. (2003). Mass spectrometry-based proteomics. Nature 422, 198-207.

Agrawal, G. K., Bourguignon, J., Rolland, N., Ephritikhine, G., Ferro, M., Jaquinod, M., et al. (2011). Plant organelle proteomics: collaborating for optimal cell function. Mass Spectrom. Rev. 30, 772-853.

Armbruster, U., Pesaresi, P., Pribil, M., Hertle, A., and Leister, D. (2011). Update on chloroplast research: new tools, new topics, and new trends. Mol. Plant 4, 1-16.

Aronsson, H., and Jarvis, P. (2002). A simple method for isolating importcompetent Arabidopsis chloroplasts. FEBS Lett. 529, 215-220.

Ayoubi, T. A. Y., and Van De Ven, W. J. M. (1996). Regulation of gene expression by alternative promoters. FASEB J. 10, 453-460.

Bannai, H., Tamada, Y., Maruyama, O., Nakai, K., and Miyano, S. (2002). Extensive feature detection of N-terminal protein sorting signals. Bioinformatics 18, 298-305.

Bantscheff, M., Lemeer, S., Savitski, M. M., and Kuster, B. (2012). Quantitative mass spectrometry in proteomics: critical review update from 2007 to the present. Anal. Bioanal. Chem. 404, 939-965.

Bantscheff, M., Schirle, M., Sweetman, G., Rick, J., and Kuster, B. (2007).
Quantitative mass spectrometry in proteomics: a critical review. Anal. Bioanal. Chem. 389, 1017-1031.

Bartsch, S., Monnet, J., Selbach, K., Quigley, F., Gray, J., von Wettstein, D., et al. (2008). Three thioredoxin targets in the inner envelope membrane of chloroplasts function in protein import and chlorophyll metabolism. Proc. Natl. Acad. Sci. U.S.A. 105, 4933-4938.

Bensimon, A., Heck, A. J., and Aebersold, R. (2012). Mass spectrometrybased proteomics and network biology. Annu. Rev. Biochem. 81, 379-405.

Berth, M., Moser, F. M., Kolbe, M., and Bernhardt, J. (2007). The state of the art in the analysis of two-dimensional gel electrophoresis images. Appl. Microbiol. Biotechnol. 76, 1223-1243.

Bindschedler, L. V., and Cramer, R. (2011). Quantitative plant proteomics. Proteomics 11, 756-775.

Bindschedler, L. V., Palmblad, M., and Cramer, R. (2008). Hydroponic isotope labelling of entire plants (HILEP) for quantitative plant proteomics; an oxidative stress case study. Phytochemistry 69, 1962 1972.

Boden, M., and Hawkins, J. (2005). Prediction of subcellular localization using sequence-biased recurrent networks. Bioinformatics 21, 2279 2286.

Boschetti, E., and Righetti, P. G. (2008). The ProteoMiner in the proteomic arena: a non-depleting tool for discovering low-abundance species. J. Proteomics 71, 255-264.

Cellar, N. A., Kuppannan, K., Langhorst, M. L., Ni, W., Xu, P., and Young, S. A.

spectrometers has over the years increased the output of proteomics data. We foresee that new robust in-solution digestion protocol coupled with fast online 2D LC-MS/MS systems will enable the next major step in barley proteomics by decreasing workload and increasing the throughput, identification rate and accuracy of quantitation of the proteomics technologies.

In the near future we expect to see more quantitative proteomics studies of barley, e.g., for molecular analysis of abiotic stress, where sensitive versus non-sensitive barley genotypes are compared, with the aim of identifying protein biomarker involved in a certain genotypic trait. Ultimately this would couple proteomics and other technologies into the multidisciplinary systems biology platform in the pursuit of sustainable crop production.

\section{ACKNOWLEDGMENT}

This work was funded by The Danish Council for Strategic Research grant number 10-093498 for the research project "NutriEfficient".

(2008). Cross species applicability of abundant protein depletion columns for ribulose-1,5-bisphosphate carboxylase/oxygenase. J. Chromatogr. B Analyt. Technol. Biomed. Life Sci. 861, 29-39.

Chen, M. J., Mooney, B. P., Hajduch, M., Joshi, T., Zhou, M. Y., $\mathrm{Xu}$, D., et al. (2009). System analysis of an Arabidopsis mutant altered in de novo fatty acid synthesis reveals diverse changes in seed composition and metabolism. Plant Physiol. 150, $27-41$.

Chevalier, F. (2010). Highlights on the capacities of "Gel-based" proteomics. Proteome Sci. 8, 23.

Ciambella, C., Roepstorff, P., Aro, E. M., and Zolla, L. (2005). A proteomic approach for investigation of photosynthetic apparatus in plants. Proteomics 5, 746-757.

Cottrell, J. S. (2011). Protein identification using MS/MS data. J. Proteomics 74, 1842-1851.

Cravatt, B. F., Simon, G. M., and Yates, J. R. III. (2007). The biological impact of mass-spectrometry-based proteomics. Nature 450, 991-1000.

de Hoog, C. L., and Mann, M. (2004).

Proteomics. Annu. Rev. Genomics Hum. Genet. 5, 267-293.

Dreher, K., and Callis, J. (2007). Ubiquitin, hormones and biotic stress in plants. Ann. Bot. 99, 787-822.

Emanuelsson, O., Nielsen, H., and Von Heijne, G. (1999). ChloroP, a neural network-based method for predicting chloroplast transit peptides and their cleavage sites. Protein Sci. 8, 978-984.

Endler, A., Reiland, S., Gerrits, B., Schmidt, U. G., Baginsky, S., and
Martinoia, E. (2009). In vivo phosphorylation sites of barley tonoplast proteins identified by a phosphoproteomic approach. Proteomics 9, 310-321.

Eriksson, J., and Fenyo, D. (2010). "Modeling experimental design for proteomics," in Computational Biology, ed. D. Fenyo (Totowa: Humana Press Inc.), 223-230.

Fasoli, E., Aldini, G., Regazzoni, L., Kravchuk, A. V., Citterio, A., and Righetti, P. G. (2010). Les maitres de l'Orge: the proteome content of your beer mug. J. Proteome Res. 9, 5262-5269.

Fatehi, F., Hosseinzadeh, A., Alizadeh, H., Brimavandi, T., and Struik, P. C. (2012). The proteome response of salt-resistant and salt-sensitive barley genotypes to long-term salinity stress. Mol. Biol. Rep. 39, 6387-6397.

Ferro, M., Brugiere, S., Salvi, D., Seigneurin-Berny, D., Court, M., Moyet, L., et al. (2010). AT_CHLORO, a comprehensive chloroplast proteome database with subplastidial localization and curated information on envelope proteins. Mol. Cell. Proteomics 9, 10631084.

Ferro, M., Salvi, D., Brugiere, S., Miras, S., Kowalski, S., Louwagie, M., et al. (2003). Proteomics of the chloroplast envelope membranes from Arabidopsis thaliana. Mol. Cell. Proteomics 2, 325-345.

Fido, R. J., Mills, E. N., Rigby, N. M., and Shewry, P. R. (2004). Protein extraction from plant tissues. Methods Mol. Biol. 244, 21-27.

Finnie, C., Bak-Jensen, K. S., Laugesen, S., Roepstorff, P., and Svensson, B. (2006). Differential appearance of 
isoforms and cultivar variation in protein temporal profiles revealed in the maturing barley grain proteome. Plant Sci. 170, 808-821.

Finnie, C., Melchior, S., Roepstorff, P., and Svensson, B. (2002). Proteome analysis of grain filling and seed maturation in barley. Plant Physiol. 129, 1308-1319.

Friso, G., Giacomelli, L., Ytterberg, A. J., Peltier, J. B., Rudella, A., Sun, Q., et al. (2004). In-depth analysis of the thylakoid membrane proteome of Arabidopsis thaliana chloroplasts: new proteins, new functions, and a plastid proteome database. Plant Cell 16, 478-499.

Froehlich, J. E., Wilkerson, C. G., Ray, W. K., McAndrew, R. S., Osteryoung, K. W., Gage, D. A., etal. (2003). Proteomic study of the Arabidopsis thaliana chloroplastic envelope membrane utilizing alternatives to traditional two-dimensional electrophoresis. J. Proteome Res. 2, 413-425.

Frohlich, A., Gaupels, F., Sarioglu, H., Holzmeister, C., Spannagl, M., Durner, J., et al. (2012). Looking deep inside: detection of low-abundance proteins in leaf extracts of Arabidopsis and phloem exudates of pumpkin. Plant Physiol. 159, 902-914.

Gerber, S. A., Rush, J., Stemman, O., Kirschner, M. W., and Gygi, S. P. (2003). Absolute quantification of proteins and phosphoproteins from cell lysates by tandem MS. Proc. Natl. Acad. Sci. U.S.A. 100, 69406945.

Gevaert, K., and Vandekerckhove, J. (2000). Protein identification methods in proteomics. Electrophoresis 21 , 1145-1154.

Giacomelli, L., Rudella, A., and van Wijk, K. J. (2006). High light response of the thylakoid proteome in Arabidopsis wild type and the ascorbate-deficient mutant vtc2-2. A comparative proteomics study. Plant Physiol. 141, 685-701.

Gilar, M., Olivova, P., Daly, A. E., and Gebler, J. C. (2005a). Orthogonality of separation in two-dimensional liquid chromatography. Anal. Chem. 77, 6426-6434.

Gilar, M., Olivova, P., Daly, A. E., and Gebler, J. C. (2005b). Twodimensional separation of peptides using RP-RP-HPLC system with different $\mathrm{pH}$ in first and second separation dimensions. J. Sep. Sci. 28, 1694-1703.

Goff, S. A., Ricke, D., Lan, T. H., Presting, G., Wang, R. L., Dunn, M., et al. (2002). A draft sequence of the rice genome (Oryza sativa L. ssp japonica). Science 296, 92-100.
Gouw, J. W., Tops, B. B., Mortensen, P., Heck, A. J., and Krijgsveld, J. (2008). Optimizing identification and quantitation of $15 \mathrm{~N}$-labeled proteins in comparative proteomics. Anal. Chem. 80, 7796-7803.

Granvogl, B., Reisinger, V., and Eichacker, L. A. (2006). Mapping the proteome of thylakoid membranes by de novo sequencing of intermembrane peptide domains. Proteomics 6, 3681-3695.

Gruhler, A., Schulze, W. X., Matthiesen, R., Mann, M., and Jensen, O. N. (2005). Stable isotope labeling of Arabidopsis thaliana cells and quantitative proteomics by mass spectrometry. Mol. Cell. Proteomics 4, 1697-1709.

Hall, M., Mishra, Y., and Schröder, W. P. (2011). "Preparation of stroma thylakoid membrane, and lumen fractions from Arabidopsis thaliana chloroplasts for proteomic analysis." in Chloroplast Research in Arabidopsis, ed. R. Paul Jarvis (New York: Humana Press), 207-222.

Horton, P., Park, K. J., Obayashi, T., Fujita, N., Harada, H., AdamsCollier, C. J., et al. (2007). WoLF PSORT: protein localization predictor. Nucleic Acids Res. 35, W585W587.

Hynek, R., Svensson, B., Jensen, O. N., Barkholt, V., and Finnie, C. (2009) The plasma membrane proteome of germinating barley embryos. Proteomics 9, 3787-3794.

Iimure, T., Nankaku, N., Hirota, N., Zhou, T. S., Hoki, T., Kihara, M., et al. (2010). Construction of a novel beer proteome map and its use in beer quality control. Food Chem. 118, 566-574.

Issaq, H., and Veenstra, T. (2008). Twodimensional polyacrylamide gel electrophoresis (2D-PAGE): advances and perspectives. Biotechniques 44 697-698, 700 .

Jacob, A. M., and Turck, C. W. (2008). Detection of post-translational modifications by fluorescent staining of two-dimensional gels. Methods Mol. Biol. 446, 21-32.

James, P. (1997). Protein identification in the post-genome era: the rapid rise of proteomics. Q. Rev. Biophys. 30 279-331.

Jones, A. M. E., Bennett, M. H., Mansfield, J. W., and Grant, M. (2006). Analysis of the defence phosphoproteome of Arabidopsis thaliana using differential mass tagging. Proteomics 6, 4155-4165.

Jorrin, J. V., Maldonado, A. M., and Castillejo, M. A. (2007). Plant proteome analysis: a 2006 update. Proteomics 7, 2947-2962.
Kamal, A. M., Cho, K., Komatsu, S. Uozumi, N., Choi, J. S., and Woo, S. H. (2012). Towards an understanding of wheat chloroplasts: a methodical investigation of thylakoid proteome. Mol. Biol. Rep. 39, 5069-5083.

Kaul, S., Koo, H. L., Jenkins, J., Rizzo, M., Rooney, T., Tallon, L. J., et al. (2000). Analysis of the genome sequence of the flowering plant Arabidopsis thaliana. Nature 408, 796-815.

Kieselbach, T., Bystedt, M., Hynds, P., Robinson, C., and Schroder, W. P. (2000). A peroxidase homologue and novel plastocyanin located by proteomics to the Arabidopsis chloroplast thylakoid lumen. FEBS Lett. 480, 271-276.

Kieselbach, T., Hagman, Andersson, B., and Schroder, W. P. (1998). The thylakoid lumen of chloroplasts. Isolation and characterization. J. Biol. Chem. 273, 6710-6716.

Kleffmann, T., Russenberger, D., von Zychlinski, A., Christopher, W. Sjolander, K., Gruissem, W., et al. (2004). The Arabidopsis thaliana chloroplast proteome reveals pathway abundance and novel protein functions. Curr. Biol. 14, 354-362.

Kline-Jonakin, K. G., Barrett-Wilt, G. A., and Sussman, M. R. (2011). Quantitative plant phosphoproteomics. Curr. Opin. Plant Biol. 14, 507-511.

Krause, F. (2006). Detection and analysis of protein-protein interaction in organellar and prokaryotic proteomes by native gel electrophoresis: (Membrane) protein complexes and supercomplexes. Electrophoresis 27, 2759-2781.

Krishnan, H. B., and Natarajan, S. S. (2009). A rapid method for depletion of Rubisco from soybean (Glycine max) leaf for proteomic analysis of lower abundance proteins. Phytochemistry 70, 1958-1964.

Kuntz, M., and Rolland, N. (2012). "Subcellular and sub-organellar proteomics as a complementary tool to study the evolution of the plastid proteome," Organelle Genetics: Evolution of Organelle Genomes and Gene Expression, ed. C. E. Bullerwell (New York: Springer)

Lander, E. S., Linton, L. M., Birren, B., Nusbaum, C., Zody, M. C., Baldwin, J., et al. (2001). Initial sequencing and analysis of the human genome. Nature 409, 860-921.

Larsen, M. R., Trelle, M. B., Thingholm, T. E., and Jensen, O. N. (2006). Analysis of posttranslational modifications of proteins by tandem mass spectrometry. Biotechniques 40, 790-798.
Laugesen, S., Bak-Jensen, K. S., Hag glund, P., Henriksen, A., Finnie, C., Svensson, B., et al. (2007). Barley peroxidase isozymes - expression and post-translational modification in mature seeds as identified by twodimensional gel electrophoresis and mass spectrometry. Int. J. Mass Spectrom. 268, 244-253.

Lemeer, S., Hahne, H., Pachl, F., and Kuster, B. (2012). Software tools for MS-based quantitative proteomics: a brief overview. Methods Mol. Biol. 893, 489-499.

Lin, Y., Liu, H., Liu, Z. H., Wang, X. C., and Liang, S. P. (2012). Shotgun analysis of membrane proteomes using a novel combinative strategy of solution-based sample preparation coupled with liquid chromatography-tandem mass spectrometry. J. Chromatogr. B Analyt. Technol. Biomed. Life Sci. 901, 18-24.

Mano, S., Miwa, T., Nishikawa, S., Mimura, T., and Nishimura, M. (2008). The plant organelles database (PODB): a collection of visualized plant organelles and protocols for plant organelle research. Nucleic Acids Res. 36, 929-937.

Manza, L. L., Stamer, S. L., Ham, A. J. L., Codreanu, S. G., and Liebler, D. C. (2005). Sample preparation and digestion for proteomic analyses using spin filters. Proteomics 5, 1742-1745.

Mayer, K. F., Waugh, R., Langridge, P., Close, T. J., Wise, R. P., Graner, A., et al. (2012). A physical, genetic and functional sequence assembly of the barley genome. Nature. 491, 711-716.

Melo-Braga, M. N., Verano-Braga, T., Leon, I. R., Antonacci, D., Nogueira, F. C. S., Thelen, J. J., et al. (2012). Modulation of protein phosphorylation, $N$-glycosylation and Lysacetylation in grape (Vitis vinifera) mesocarp and exocarp owing to Lobesia botrana infection. Mol. Cell. Proteomics 11, 945-956.

Metodiev, M., and Demirevskakepova, K. (1992). Rbisco quantitation in leaves of different barley varieties by enzyme-linked-immunosorbentassay. J. Exp. Bot. 43, 155-158.

Millar, A. H., Heazlewood, J. L., Kristensen, B. K., Braun, H. P., and Moller, I. M. (2005). The plant mitochondrial proteome. Trends Plant Sci. 10, 36-43.

Mithoe, S. C., and Menke, F. L. H. (2011). Phosphoproteomics perspective on plant signal transduction and tyrosine phosphorylation. Phytochemistry 72, 9971006. 
Moller, A. L. B., Pedas, P., Andersen, B., Svensson, B., Schjoerring, J. K., and Finnie, C. (2011a). Responses of barley root and shoot proteomes to longterm nitrogen deficiency, short-term nitrogen starvation and ammonium. Plant Cell Environ. 34, 20242037.

Moller, I. M., Rogowska-Wrzesinska, A., and Rao, R. S. P. (2011b). Protein carbonylation and metal-catalyzed protein oxidation in a cellular perspective. J. Proteomics 74, 22282242.

Nawrocki, A., Thorup-Kristensen, K., and Jensen, O. N. (2011). Quantitative proteomics by 2DE and MALDI MS/MS uncover the effects of organic and conventional cropping methods on vegetable products. J. Proteomics 74, 2810-2825.

Neilson, K. A., Mariani, M., and Haynes, P. A. (2011). Quantitative proteomic analysis of cold-responsive proteins in rice. Proteomics 11, 1696-1706.

Nelson, C. J., Huttlin, E. L., Hegeman, A. D., Harms, A. C., and Sussman, M. R. (2007). Implications of $\mathrm{N}$ 15-metabolic labeling for automated peptide identification in Arabidopsis thaliana. Proteomics 7, 12791292.

Neuburger, M., Journet, E. P., Bligny, R., Carde, J. P., and Douce, R. (1982). Purification of plant-mitochondria by isopycnic centrifugation in density gradients of percollLL. Arch. Biochem. Biophys. 217, 312-323.

Ng, D. W. K., Zhang, C., Miller, M., Shen, Z., Briggs, S. P., and Chen, Z. J. (2012). Proteomic divergence in Arabidopsis autopolyploids and allopolyploids and their progenitors. Heredity (Edinb) 108, 419-430.

Norrgran, J., Williams, T. L., Woolfitt, A. R., Solano, M. I., Pirkle, J. L., and Barr, J. R. (2009). Optimization of digestion parameters for protein quantification. Anal. Biochem. 393, 48-55.

Okada, Y., Limure, T., Takoi, K., Kaneko, T., Kihara, M., Hayashi, K., et al. (2008). The influence of barley malt protein modification on beer foam stability and their relationship to the barley dimeric alpha-amylase inhibitor-1 (BDAI-1) as a possible foam-promoting protein. J. Agric. Food Chem. 56, 1458-1464.

Ong, S. E., Blagoev, B., Kratchmarova, I., Kristensen, D. B., Steen, H., Pandey, A., et al. (2002). Stable isotope labeling by amino acids in cell culture, SILAC, as a simple and accurate approach to expression proteomics. Mol. Cell. Proteomics 1, 376-386.

Ong, S. E., and Mann, M. (2005). Mass spectrometry-based proteomics turns quantitative. Nat. Chem. Biol. 1 , 252-262.

Ostergaard, O., Melchior, S., Roepstorff, P., and Svensson, B. (2002). Initial proteome analysis of mature barley seeds and malt. Proteomics 2, 733-739.

Patterson, J., Ford, K., Cassin, A., Natera, S., and Bacic, A. (2007). Increased abundance of proteins involved in phytosiderophore production in boron-tolerant barley. Plant Physiol. 144, 1612-1631.

Patterson, S. D., and Aebersold, R. H. (2003). Proteomics: the first decade and beyond. Nat. Genet. 33, 311-323

Patton, W. F. (2002). Detection technologies in proteome analysis. J. Chromatogr B Analyt. Technol. Biomed. Life Sci. 771, 3-31.

Peltier, J. B., Cai, Y., Sun, Q., Zabrouskov, V., Giacomelli, L., Rudella, A., etal. (2006). The oligomeric stromal proteome of Arabidopsis thaliana chloroplasts. Mol. Cell. Proteomics 5, 114-133.

Peltier, J. B., Emanuelsson, O., Kalume, D. E., Ytterberg, J., Friso, G., Rudella, A., et al. (2002). Central functions of the lumenal and peripheral thylakoid proteome of Arabidopsis determined by experimentation and genomewide prediction. Plant Cell 14, 211-236

Peltier, J. B., Friso, G., Kalume, D. E. Roepstorff, P., Nilsson, F., Adamska, I., etal. (2000). Proteomics of the chloroplast: systematic identification and targeting analysis of lumenal and peripheral thylakoid proteins. Plant Cell 12, 319-341.

Peltier, J. B., Ytterberg, A. J., Sun, Q., and van Wijk, K. J. (2004). New functions of the thylakoid membrane proteome of Arabidopsis thaliana revealed by a simple, fast, and versatile fractionation strategy. J. Biol. Chem. 279, 49367-49383.

Perrocheau, L., Rogniaux, H., Boivin, P. and Marion, D. (2005). Probing heatstable water-soluble proteins from barley to malt and beer. Proteomics 5, 2849-2858.

Petry-Podgorska, I., Zidkova, J., Flodrova, D., and Bobalova, J. (2010). 2D-HPLC and MALDI-TOF/TOF analysis of barley proteins glycated during brewing. J. Chromatogr. B Analyt. Technol. Biomed. Life Sci. 878, 3143-3148.

Ploscher, M., Granvogl, B., Zoryan, M., Reisinger, V., and Eichacker, L. A. (2009). Mass spectrometric characterization of membrane integral low molecular weight proteins from photosystem II in barley etioplasts. Proteomics, 9 625-635.
Ploscher, M., Reisinger, V., and Eichacker, L. A. (2011). Proteomic comparison of etioplast and chloroplast protein complexes. J. Proteomics 74, 1256-1265.

Podwojski, K., Stephan, C., and Eisenacher, M. (2012). Important issues in planning a proteomics experiment: statistical considerations of quantitative proteomic data. Methods Mol. Biol. 893, 3-21.

Pottiez, G., Wiederin, J., Fox, H. S., and Ciborowski, P. (2012). Comparison of 4-plex to 8-plex iTRAQ quantitative measurements of proteins in human plasma samples. J. Proteome Res. 11, 3774-3781.

Reisinger, V., and Eichacker, L. A. (2007). How to analyze protein complexes by $2 \mathrm{D}$ blue native SDS-PAGE. Proteomics 7(Suppl. 1), 6-16.

Ross, P. L., Huang, Y. L. N., Marchese, J. N., Williamson, B., Parker, K., Hattan, S., et al. (2004). Multiplexed protein quantitation in Saccharomyces cerevisiae using amine-reactive isobaric tagging reagents. Mol. Cell. Proteomics 3, 1154-1169.

Sachon, E., Mohammed, S., Bache, N. and Jensen, O. N. (2006). Phosphopeptide quantitation using aminereactive isobaric tagging reagents and tandem mass spectrometry: application to proteins isolated by gel electrophoresis. Rapid Commun. Mass Spectrom. 20, 1127-1134.

Saeed, M., Dahab, A. H. A., Guo, W. Z., and Zhang, T. Z. (2012). A cascade of recently discovered molecular mechanisms involved in abiotic stress tolerance of plants. OMICS 16 , 188-199.

Saisho, D., and Takeda, K. (2011). Barley: emergence as a new research material of crop science. Plant Cell Physiol. 52, 724-727.

Schmidt, A., Kellermann, J., and Lottspeich, F. (2005). A novel strategy for quantitative proteomics using isotope-coded protein labels. Proteomics 5, 4-15.

Schubert, M., Petersson, U. A., Haas, B. J., Funk, C., Schroder, W. P. and Kieselbach, T. (2002). Proteome map of the chloroplast lumen of Arabidopsis thaliana. J. Biol. Chem. 277, 8354-8365.

Schulte, D., Close, T. J., Graner, A., Langridge, P., Matsumoto, T., Muehlbauer, G., et al. (2009). The international barley sequencing consortium-at the threshold of efficient access to the barley genome. Plant Physiol. 149, 142-147.

Shevchenko, A., Tomas, H., Havlis, J. Olsen, J. V., and Mann, M. (2006). Ingel digestion for mass spectrometric characterization of proteins and proteomes. Nat. Protoc. 1, 2856-2860.

Shevchenko, A., Wilm, M., Vorm, O., and Mann, M. (1996). Mass spectrometric sequencing of proteins from silver stained polyacrylamide gels. Anal. Chem. 68, 850-858.

Silva, J. C., Gorenstein, M. V., Li, G. Z., Vissers, J. P. C., and Geromanos, S. J. (2006). Absolute quantification of proteins by LCMSE - a virtue of parallel MS acquisition. Mol. Cell. Proteomics 5, 144-156.

Small, I., Peeters, N., Legeai, F., and Lurin, C. (2004). Predotar: a tool for rapidly screening proteomes for N-terminal targeting sequences. Proteomics 4, 1581-1590.

Speers, A. E., and Wu, C. C. (2007). Proteomics of integral membrane proteins theory and application. Chem. Rev. 107, 3687-3714.

Syed, N. H., Kalyna, M., Marquez, Y., Barta, A., and Brown, J. W. S. (2012). Alternative splicing in plants - coming of age. Trends Plant Sci. 17, 616-623.

Thelen, J. J., and Peck, S. C. (2007). Quantitative proteomics in plants: choices in abundance. Plant Cell 19, 3339-3346.

van Bentem, S. D., Roitinger, E., Anrather, D., Csaszar, E., and Hirt, H. (2006). Phosphoproteomics as a tool to unravel plant regulatory mechanisms. Physiol. Plant. 126, 110-119.

van Wijk, K. J. (2004). Plastid proteomics. Plant Physiol. Biochem. 42, 963-977.

Washburn, M. P., Wolters, D., and Yates, J. R. (2001). Large-scale analysis of the yeast proteome by multidimensional protein identification technology. Nat. Biotechnol. 19, 242-247.

Wendelboe-Nelson, C., and Morris, P. C. (2012). Proteins linked to drought tolerance revealed by DIGE analysis of drought resistant and susceptible barley varieties. Proteomics 12, 3374-3385.

Wienkoop, S., Larrainzar, E., Niemann, M., Gonzalez, E. M., Lehmann, U., and Weckwerth, W. (2006). Stable isotope-free quantitative shotgun proteomics combined with sample pattern recognition for rapid diagnostics. J. Sep. Sci. 29, 27932801.

Wiese, S., Reidegeld, K. A., Meyer, H. E., and Warscheid, B. (2007). Protein labeling by iTRAQ: A new tool for quantitative mass spectrometry in proteome research. Proteomics 7, 340-350.

Wisniewski, J. R., Zougman, A., Nagaraj, N., and Mann, M. (2009). Universal sample preparation method for 
proteome analysis. Nat. Methods 6, 359-362.

Wortman, J. R., Haas, B. J., Hannick, L. I., Smith, R. K., Maiti, R., Ronning, C. M., et al. (2003). Annotation of the Arabidopsis genome. Plant Physiol. 132, 461-468.

Xiao, Z., Conrads, T. P., Lucas, D. A., Janini, G. M., Schaefer, C. F., Buetow, K. H., et al. (2004). Direct ampholyte-free liquid-phase isoelectric peptide focusing: application to the human serum proteome. Electrophoresis 25, 128-133.

Yeung, Y. G., and Stanley, E. R. (2010). Rapid detergent removal from peptide samples with ethyl acetate for mass spectrometry analysis. Curr. Protoc. Protein Sci. Chapter 16:Unit 16.12.

Ytterberg, A. J., and Jensen, O. N. (2010). Modification-specific proteomics in plant biology. J. Proteomics 73, 22492266.

Zybailov, B., Rutschow, H., Friso, G., Rudella, A., Emanuelsson, O., Sun, Q., etal. (2008). Sorting signals, N-terminal modifications and abundance of the chloroplast proteome. PLOS ONE 3:e1994. doi: 10.1371/journal.pone. 0001994
Conflict of Interest Statement: The authors declare that the research was conducted in the absence of any commercial or financial relationships that could be construed as a potential conflict of interest.

Received: 10 January 2013; paper pending published: 30 January 2013; accepted: 26 February 2013; published online: 18 March 2013.

Citation: Petersen J, RogowskaWrzesinska A and Jensen ON (2013) Functional proteomics of barley and barley chloroplasts - strategies, methods and perspectives. Front. Plant Sci. 4:52. doi: 10.3389/fpls.2013.00052

This article was submitted to Frontiers in Plant Proteomics, a specialty of Frontiers in Plant Science.

Copyright () 2013 Petersen, RogowskaWrzesinska and Jensen. This is an openaccess article distributed under the terms of the Creative Commons Attribution License, which permits use, distribution and reproduction in other forums, provided the original authors and source are credited and subject to any copyright notices concerning any third-party graphics etc. 